\title{
La métrica de la muerte: los epitafios hebreos medievales de la Península Ibérica con versos escandidos"
}

\author{
José Martínez Delgado** \\ Universidad de Granada \\ ORCID ID: http://orcid.org/0000-0001-7595-3912
}

Los epitafios son textos destinados a ser grabados en un túmulo, cipo, ladrillo o piedra y siempre preceden al nombre del difunto y la fecha de su óbito. En ocasiones van seguidos de un texto en prosa rimada. El objetivo de este trabajo es poner de manifiesto la utilidad de la métrica para ayudar a interpretar, incluso reconstruir, el texto de las inscripciones con epitafios introducidos por versos escandidos y, así, se analiza la métrica de los cuatro casos de los 189 de este tipo recogidos por Casanovas Miró (75, 87, 134 y 174). Dos de los textos provienen del noreste peninsular (Gerona) y están datados en los años 1198 y 1371; un tercero, sin data, proviene del Levante (Sagunto); y un último fechado en 1302 (quizá haya que leer 1356) de Toledo. En todo caso, la mayoría de ellos provienen de una zona muy alejada en el espacio y el tiempo de Alandalus, demostrando cómo la comunidad judía asimiló estas categorías estéticas y las incorporó como marca de identidad.

Palabras Clave: Epigrafía hebrea; métrica andalusí; epitafios; poesía hebrea.

The Metric of the Death: Medieval Hebrew Epitaphs from the Iberian Peninsula WITH SCANNEd Verses.- Epitaphs are texts meant to be engraved on burial mound, memorial stone, brick or stone and always precede the name of the deceased and the eve of his/ her death. Sometimes they are followed by a rhymed prose text. The aim of this paper is to show how metrics can help to interpret or even reconstruct the text of Hebrew inscriptions with epitaphs introduced by rhymed verses. This way I will study the four rhymed epitaphs (75, 87, 134 y 174), of the 189 samplers, collected by Casanovas Miró. Two of them come from the northeast area of the peninsula (Girona) and dated in 1198 and 1371; the third has no data and come from eastern Spain (Sagunto); the last one, dated in 1302 (perhaps 1356), and come from Toledo. In any case, most of them come from an area separated significantly in time and space from Alandalus, showing how the Jewish community assimilated these aesthetic categories and adopted them as their own identity mark.

KeYwords: Hebrew inscriptions; Andalusi Metrics; Epitaphs; Hebrew poetry.

"Este trabajo se encuadra dentro del proyecto de investigación «Recuperación y estudio del legado lingüístico judeo-árabe de al-Andalus» (FFI2014-51818-P).

pdelgado@ugr.es

Copyright: (C) 2018 CSIC. Este es un artículo de acceso abierto distribuido bajo los términos de la licencia de uso y distribución Creative Commons Reconocimiento 4.0 Internacional (CC BY 4.0). 


\section{INTRODUCCIÓN}

La poesía hebrea escandida con métrica árabe es sin duda una de las mayores marcas de identidad del judaísmo andalusí ${ }^{1}$. Esta forma de componer poesía incluso sobrevivió al estado andalusí y se fue adaptando y transmitiendo durante siglos, primero por los reinos de la Península Ibérica $^{2}$ y más tarde por toda la diáspora sefardî́. De hecho, algunas de sus muestras se siguen empleando incluso hoy en la liturgia sinagogal.

Sin embargo, el proceso de transmisión de estas composiciones es muy complejo y en muchas ocasiones se prestan con facilidad a la corrupción textual. Es un fenómeno que ocurría incluso ya en vida de los poetas andalusíes del siglo x; no sólo se atribuían versos a poetas que no los habían compuesto $^{4}$, sino que además, cuando las lecturas no cuadraban bien por

\footnotetext{
${ }^{1}$ Véase una visión de conjunto y relativamente actualizada en Ángel SÁENZ-BADILLOS, «El estudio de la poesía y la prosa hispanohebrea en los últimos cincuenta años», en Ángel Sáenz-Badillos Pérez, Lengua y Literatura de los judíos de al-Andalus (siglos X-XII), ed. José Martínez Delgado (Granada: Ediciones Universidad de Granada, 2015) págs. 5581: 55-78.

${ }^{2}$ Es el caso de David b. Yom Țob b. Bilya de Portugal, que divide las vocales en reyes (qameș, patah, șere, segol, holem, y hireq) y siervos (šěwa' y qibbus šěfatayim o šureq) y recoge, al igual que Qimhi hasta dieciocho variantes de lo que hoy consideramos nueve metros (Nehemya Allony, «Derek la‘ăśot ḥaruzim lě-David ibn Bilya», Qobeș al-yad 16 [1966] págs. 225-246). En los últimos años de la Granada nazarí, Să ‘adya b. Danān recogerá, en la introducción de su diccionario, la triple concepción de las vocales hebreas: masorética, gramatical y métrica, dedicando un capítulo entero al arte de componer poesía, siguiendo a grandes rasgos esta adaptación para público no arabófono y desviándose en no pocos puntos del modelo autóctono al intentar aunarlos (Moshe CoHEN, [ed.], The Grammatical Introductions to "The Book of sources" of Să 'adya ibn Danān [en hebreo] [Jerusalem: Kfir Press, Meqor Baruch Publications, 2000] págs. 66-76 para la versión árabe, y 155-167 para la versión hebrea).

${ }^{3}$ A partir del siglo xv, este modelo será el que se transmita entre las diferentes comunidades judías dispersas por Europa en las obras de célebres maestros como Aḅ̌salom b. Mošeh Mizraḥi, Abravanel y David b. Yahya de Portugal, o ya en los siglos XVI y XVII, en las de los italianos Enmanuel b. Yěquti'el, Azaría de Rossi, Samuel Archivolti y Enmanuel Fransis o la del holandés Salomón de Oliveyra y véase una buena recensión sobre todos estos autores en Carlos Del Valle RodríGuez, El diván poético de Dunaš ben Labrat (Madrid: CSIC, 1988) págs 349-459.

${ }^{4}$ Así lo afirma Ibn Ğanāḥ (c. 970 - d. 1038) en su Kitāb al-luma ‘ (Joseph DerenbourG, [ed.], Livre des parterres fleuris; grammaire hébräque en arabe d'Abou 'l-Walid Merwan ibn Djanah de Cordoue [Paris: F. Vieweg, 1886] págs. 304-305): «Más infame aún si
} 
sentido bien por métrica, se alteraban en un intento de corregir al poeta que sabía perfectamente lo que estaba componiendo 5 .

Para colmo, autores como Abraham ibn 'Ezra o Mošeh Qimḥ̄, andalusíes exiliados por Europa tras la llegada de los almohades, se encargaron de simplificar, incluso reducir al absurdo de dos unidades básicas (yated y

cabe es el livor que sufrí por parte de los envidiosos y sus ansias de calumniarme: sabéis bien que la poesía no está entre mis habilidades ni el poema entre mis productos, no estoy relacionado con ella ni la conozco y tampoco considero que sea algo que temer o escatimar sino que me siento por encima de ella y superior a su discurso si bien es cierto que durante la juventud compuse piezas que conservamos sabiendo que son obra mía; pero la envidia se apoderó de un grupo de gente que recogió una de estas piezas, que era idónea, en un libro, se la atribuyeron a Ibn Halfūn, el poeta, y se la enviaron a gente de Toledo. Me contó uno de los discípulos, consciente de que el poema era mío, que se juntó un día en Toledo con personas que estaban leyendo dicho poema y se lo atribuían al susodicho poeta mencionado, él les dijo "éste es de fulano", refiriéndoseme a mí, "y nosotros damos fe de que él lo compuso y que de él lo tomamos" pero no le hicieron caso alguno». Este apunte le costó el reproche posterior de Mošeh b. 'Ezra en su Kitāb al-muhādara wa-l-mud̄ākara f. 74 (ed. de Montserrat Abumalnam Mas [Madrid: CSIC, 1986]).

${ }^{5}$ De nuevo en Kitāb al-luma ' (Derenbourg, Livre des parterres fleuris, págs. 207-208), Ibn Ğanāḥ dice: «Has de saber que no podemos prohibir al poeta que altere la forma del paradigma غֶׁ cuando se anexiona a un nombre absoluto ya que hemos encontrado esta forma alterada por distintos pasajes de la Biblia cuando se anexiona a nombres absolutos tal y como hemos mencionado previamente y siguiendo esta tendencia dijo Yișhaq b.

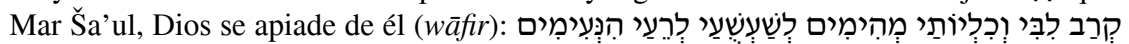
[La entraña de mi corazón y mis riñones se alborotan / por mis deleites, mis agradables

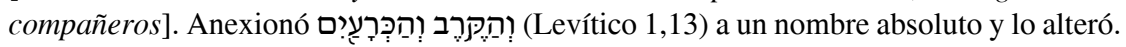
A este verso le ha ocurrido algo simpático que carece de malicia, que te voy a reseñar, y es que la mayoría de los rapsodas transmiten סִגרך לִבְִּ (la membrana de mi corazón), así se encuentra en la mayoría de las copias y así lo transmitía yo mismo a partir de otro. Cuando

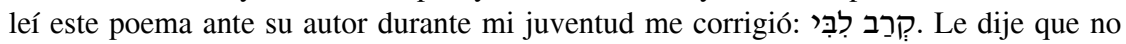
había visto en ninguna de las copias más que סִגר לִִ̣ y que de dónde venía esta variante. Me contó, en paz descanse, que estaba elogiando en este poema a Jacob [b. Ğaw?] y a su hijo, los anfitriones, en paz descansen, y que se lo envió desde su ciudad a Córdoba llegando al homenajeado. Abū Zakariyā' b. Ḥaniga' y Abū Ibrahīm b. Halfūn [estaban

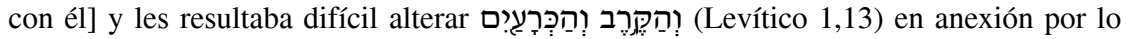
que vieron oportuno cambiar la expresión por סֶקר , por reconciliación pero desbaratando el significado original. Dijo: en Córdoba ya se copió el poema con esta alteración y sustitución. Me contó Abū Ibrahīm b. Sahl al-Talmasān̄i, en paz descanse, que en Egipto vio a lingüistas que también desaprobaban a este poeta por decir esto y pensaron que lo

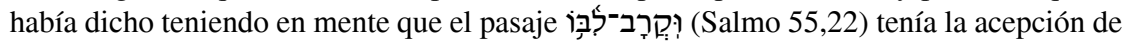

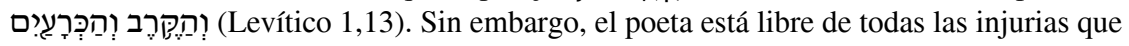
se han vertido contra él». 
těnu 'ah), el complejísimo y rico catálogo de formas y variantes de lo que los árabes consideran la ciencia métrica ( 'ilm al- 'arūụ). Esto supuso que desde el Renacimiento europeo y sobre todo en época moderna, no se entendiese correctamente la métrica de algunas composiciones redactadas entre los siglos X-XII o que, gracias a la alternancia de yated y těnu' $a h$, se escandiese esta poesía según los criterios de las poesías griega y latina ${ }^{6}$.

En este contexto, el caso de los epitafios es especial debido a que, en principio, el texto ha sido grabado en piedra en un momento muy próximo a su redacción y muy posiblemente bajo la supervisión del autor. Las composiciones que encontramos en los epitafios hebreos son una variante de las famosas y bien conocidas elegías ${ }^{7}$ (martiyah en árabe) que se remontan en el caso de los poetas hebreos andalusíes incluso a etapas anteriores a la adaptación de la métrica hebrea por Dunaš b. Labraṭ alrededor del año $958^{8}$. De hecho, algunos de ellos y gracias a su altísima calidad se

\footnotetext{
${ }^{6}$ Para los diferentes modelos prosódicos utilizados a lo largo de los siglos, véase José Martínez Delgado, Un manual judeo-árabe de métrica hebrea andalusí (Kitāb 'arūd al-ši' 'r al-'ibrī) de la Genizah de el Cairo. Fragmentos de las colecciones Firkovich y Taylor-Schechter. Edición diplomática, traducción y estudio (Córdoba: UCOPressCNERU-CSIC, 2017) págs. 17-32.

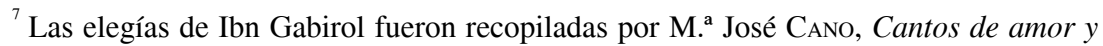
muerte Selomoh ibn Gabirol (Granada: Editorial Universidad de Granada, 2007). Las de Mošeh ibn 'Ezra fueron recopiladas por Ángeles NAvarro Peiró, El tiempo y la muerte. Las elegías de Mošeh ibn 'Ezra (Granada: Universidad de Granada, 1994). Véase además el estudio de Aurora SAlvatierra Ossorio, La muerte, el destino y la enfermedad en la obra poética de Y. ha-Levi y Š. Ibn Gabirol (Granada: Universidad de Granada, 1994), especialmente las págs. 61-138.

${ }^{8}$ Según Ezra Fleischer («Lě-qadmoniot širatenu bi-Sfarad. 'Iyyun ba-širim šel rabbi Měnahemem ben Saruq», Asupot 2 [1988] págs. 227-269), tal y como señalé en la nota 10 de mi artículo «Muestras del estrofismo andalusí y su métrica según la poesía hebrea» (Al-Qanțara 37:1 [2016] págs. 39-58: 43) que reproduzco aquí, en la primera mitad del siglo x ya se producía poesía secular en Alandalus y es posible que en este aspecto se adelantase a las metrópolis orientales. Desde un punto de vista formal era una poesía oriental o tradicional, aunque en su contexto histórico era la más moderna e innovadora entre las comunidades judías del islam. Por ejemplo, la endecha de Měnaḥem ben Saruq a la madre de Ḥasday ibn Šapruț, por su temática, recuerda más a un poeta árabe contemporáneo o a un poeta hebreo posterior a Dunaš ben Labrat, porque aun siendo una composición tradicional tiene una función social y un contexto que no es el tradicional. En la época de Měnaḥem ben Saruq (califato de 'Abdarraḥmān III) se componían auténticos panegíricos hebreos desconocidos en oriente. Según Fleischer, en estos panegíricos no hay influencia árabe, las composiciones carecen de métrica y
} 
nos han transmitido en las colecciones o divanes de sus autores, como el caso de dos compuestos por Mošeh ibn 'Ezra'; mientras que otros nos han llegado a través de testimonios oculares, tanto de época medieval ${ }^{10}$ como moderna ${ }^{11}$. En líneas generales, se trata de textos destinados a ser grabados en un túmulo, cipo, ladrillo o piedra y siempre preceden al nombre del difunto y la fecha de su óbito. En ocasiones van seguidos de un texto en prosa rimada. La mayor colección de inscripciones hebreas fúnebres de la Península Ibérica hasta la fecha es la realizada por Jordi Casanovas Miró $^{12}$, y en cuyas lecturas, al ser los únicos testimonios físicos reales que nos quedan, basaré el siguiente análisis.

la disposición de sus versos es la tradicional, ya que la rima única se emplea en hebreo desde tiempos antiguos y el uso de la cesura tampoco es indicio de influencia árabe. De hecho, el uso de la cesura en alguna composición es libre, por lo que no es obligatoria como en árabe; simplemente viene a romper la monotonía. Las composiciones de Mĕnaḥem ben Saruq confirman que la comunidad judía de Alandalus, desde una perspectiva social, estaba preparada para el cambio introducido por Dunaš ben Labraț. Por lo tanto la innovación de Dunaš ben Labraț se reduce únicamente al aspecto formal: la métrica. De hecho, los discípulos de Měnahemem ben Saruq no dicen nada respecto a la estructura estrófica del poema ni a las imágenes árabes, tan sólo se centran en aspectos lingüísticos y métricos. La poesía religiosa es, según los materiales que conocemos, posterior a la secular. Aunque se importase piyyuț de oriente es difícil imaginar que no hubiese poetas religiosos antes de la segunda mitad del siglo $\mathrm{x}$, simplemente no tenemos noticias de ellos. Las más tempranas muestras son dos breves composiciones atribuidas a Mĕnahem ben Saruq sin innovación alguna y bajo la influencia total de oriente; ni siquiera aún bajo la de Sa'adia Ga'on (882-942). El hecho de que Mĕnahem ben Saruq firme como qațan 'pequeño' pueden hacernos pensar que son obras de juventud y que aun quizá no conociese la obra de Sa'adia Ga'on.

${ }^{9}$ Es el caso del epitafio del célebre rabino de Lucena Yiṣhạaq al-Fāsī (año 1103) o del de Abū Zakariyā' b. Yaqwā (año 1109) y véase la traducción de ambos en NAvarro Peiró, El tiempo y la muerte, págs. 149-151 y 63-64 respectivamente.

${ }^{10}$ El testigo ocular más famoso es Mošeh b. Habib cuyo testimonio es anterior a 1492 y nos transmite la leyenda legendaria del cipo de Sagunto, y véase Josep Corell, «La inscripción hebrea atribuida a un jefe militar de Amasias (Sagunt, Valencia)», Miscelánea de Estudios Árabes y Hebraicos 43:2 (1994) págs. 83-96 y más adelante la propuesta de transcripción.

${ }^{11}$ El testimonio más valioso de esta época sin duda es el de Samuel David Luzzatto, Abne Zikaron (Prag: M. I. Landau, 1841) que transmite hasta setenta y seis epitafios del cementerio judío de Toledo, muchos de ellos desaparecidos en la actualidad.

${ }^{12}$ Jordi CaSAnovas Miró, Las inscripciones funerarias hebraicas medievales de España (= Monumenta paleographica Medii Aevi. Series Hebraica. Inscriptiones hebraicis litteris 
El objetivo de este trabajo es poner de manifiesto la utilidad de la métrica para ayudar a interpretar, incluso reconstruir, el texto de estas inscripciones, por lo general muy maltratadas por el paso del tiempo y la mano del hombre. Los 189 testimonios recopilados por Casanovas en su catálogo son textos muy heterogéneos y por lo general en un estado de conservación paupérrimo. La mayoría son obra de grabadores profesionales donde las erratas brillan por su ausencia; salvo en el caso de la inscripción número 170 donde por sistema se emplea qof cuando corresponde kaf; waw donde se espera bet; y șade donde corresponde same $\underline{k}^{13}$.

De todos los testimonios epigráficos recopilados en el volumen de Casanovas tan sólo cuatro muestras (números $75,87,134$ y 174) son claramente textos sometidos a la estricta métrica de tradición andalusí; quizá haya más, pero estos son los únicos que pueden confirmarse a ciencia cierta por la presencia o conservación de la rima. Dos de los textos provienen del noreste peninsular (Gerona) y están datados en los años 1198 y 1371; un tercero, sin data, proviene del Levante (Sagunto); y un último fechado en 1302 (quizá haya que leer 1356 como veremos) de Toledo. En todo caso, la mayoría de ellos provienen de una zona muy alejada en el espacio y el tiempo de Alandalus, demostrando cómo la comunidad judía asimiló estas categorías estéticas y las incorporó como marca de identidad.

\section{ANÁLISIS DE LAS MUESTRAS}

\subsection{Epitafio de Rabí Yosef ben Teqa}

La primera muestra de este estudio es la número 75 en el catálogo de Casanovas: «Epitafio de Rabí Yosef ben Teqa» ${ }^{14}$. Apareció en la provin-

exaratae quo tempore scriptae fuerint exhibentes 1 [Turnhout: Brepols, 2014]). Tras la publicación de este volumen apareció la lápida hebrea de Córdoba más antigua conocida hasta el momento, epitafio de Yěhudah bar Abūn (no Akūn) datado en el año 845, y véase el informe en Isabel Larrea Castillo y Enrique Hiedra Rodríguez, «La lápida hebrea de época emiral del Zumbacón. Apuntes sobre arqueología funeraria judía en Córdoba», Anejos de Anales de Arqueología Cordobesa 2 (2009) págs. 327-342.

${ }^{13}$ CASAnOvas Miró, Las inscripciones funerarias hebraicas, págs. 179-180.

${ }^{14}$ CAsanovas Miró, Las inscripciones funerarias hebraicas, págs. 83-85. 
cia de Gerona y se trata del epitafio de Yosef b. Teqa' cuyo óbito se fecha el día 17 de siwan de la año 4958 de la Creación (correspondiente al 31 de mayo del año 1198).

Se trata de una breve composición de cuatro versos seguida de la data del óbito e identificación del difunto y un breve texto en prosa rimada. A continuación ofrezco la propuesta de lectura de los cuatro versos con los que comienza el epitafio:

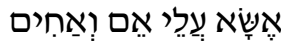

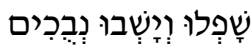

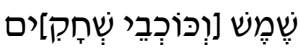

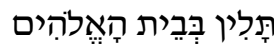

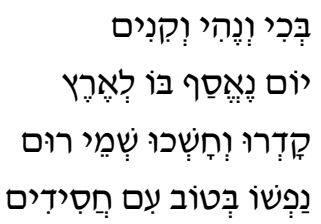

Traducción:

Llanto, lamento y elegías / entonaré para la madre y los hermanos ${ }^{15}$

Cuando se sumó a la tierra / fueron abatidos y quedaron confundidos

Se ennegrecieron y oscurecieron los Cielos / el sol [y las estrellas del cielo]

Su alma, de bienestar, con los justos, I gozará en la Casa de Dios

El metro es muğtatt (conocido en terminología israelí como qața') en

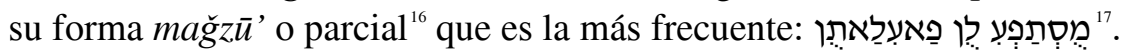
La rima de la composición es -im y se emplea el ritmo tașri ${ }^{\text {(18 }}$. A continuación ofrezco su escansión y propuesta de transcripción ${ }^{19}$ :

\footnotetext{
${ }^{15}$ Coincido con el editor (CASAnOvas Miró, Las inscripciones funerarias hebraicas, pág. 85) en que puede leerse también אָח וٕאחחִים 'para todos y cada uno de los hermanos'.

${ }^{16}$ Es decir, forma parcial del verso, al que se le ha suprimido un pie de cada hemistiquio.

${ }^{17}$ Para la catalogación de sílabas y pies emplearé el alefato y reproduciré la vocalización original árabe por medio de las vocales hebreas qibbuș (damma), patah (fatha) y hireq

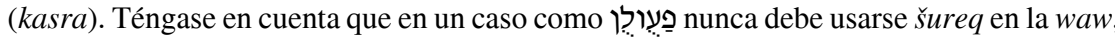
ya que ésta, a efectos métricos en este pie, es una letra quiescente como la nun final, por lo que no puede recibir vocal alguna.

${ }^{18}$ Este ritmo consiste en hacer coincidir la rima y el pie de 'arū hemistiquios a comienzo del poema.

${ }^{19}$ Para las transcipciones sigo los criterios fijados en José Martínez Delgado, «On the phonology of Hebrew in Alandalus as reflected by the adaptation of Arabic grammar and poetry», en Archaism and Innovation in the Semitic Languages, Selected Papers, eds. Juan Pedro Monferrer-Sala y Wilfred G. E. Watson (Córdoba:
} 


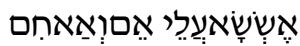

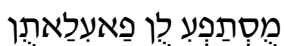

bakíwaná hiwaqínim assa 'alí imwa'áhim

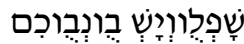

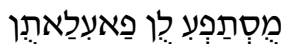

yumna'asáf bula'áras šafluwiyáš bunabúkim

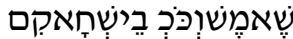

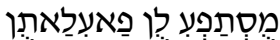

qad ruwaḥáš kِušamírum šamašwakók bišaháqim

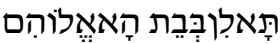

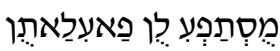

$$
\text { בְּבִיוְנֶא הִיוְקִינִם }
$$

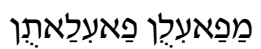

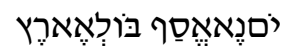

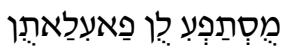

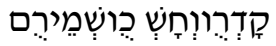

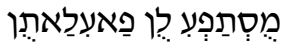

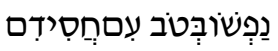

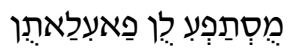

nafšubatúb 'imhasídim talinbabít ha'ilúhim

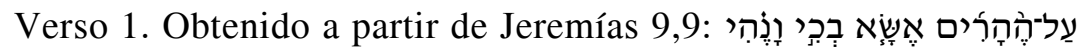
por las montañas entonaré llanto y lamento y por los majadales de la estepa endecha'. El primer pie ha sido modificado

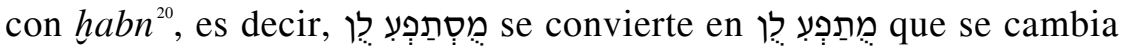

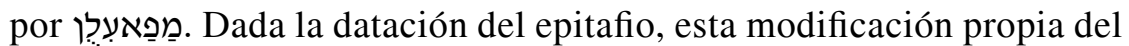
modelo autóctono andalusí es factible en esta composición. Para que encaje en el modelo románico, basado en la alternancia de yated (Y) y těnu 'ot $(\mathrm{T})$, habría que leer בִָּ en pausa y así respondería al patrón TYT TTY ${ }^{21}$. No parece que pueda tratarse del segolado בְָּּ y que deba-

CNERU-DTR 2013) págs. 73-86. Para la posición del acento en la segunda letra del watid o yated sigo a los discípulos de Měnahem b. Saruq; véase Santiaga Benavente RoBles, Tešubot de los Discípulos de Měnahem contra Dunaš ben Labraț. Edición del texto y traducción castellana (Granada: Universidad de Granada, 1986) págs. 14*15* y 18-19; Ángel SÁEnz-Badillos, «Los discípulos de Měnaḥem sobre la métrica hebrea», Sefarad 46:2 (1986) págs. 421-431; Federico CoRrIENTE, «Métrica hebrea cuantitativa, métrica de la poesía estrófica andalusí y ‘arūḍ», Sefarad 46:1 (1986) págs. 123-132.

${ }^{20}$ Esta modificación consiste en eliminar la segunda consonante del pie original cuando ésta es quiescente.

${ }^{21}$ En el modelo autóctono este metro contiene una unidad prosódica conocida como watid mafrūq que consiste en la sucesión de tres letras, donde la primera está vocalizada, la segunda quiescente y la tercera vocalizada, correspondiéndose con la 
mos atribuirlo a error del grabador, ya que la influencia del pasaje de Jeremías es evidente. Como indica el editor ${ }^{22}$, en el pie que ocupa la posición de darb (soger en terminología hebrea), puede leerse tanto אֵ, lectura que seguimos, como wָ, con valor inclusivo.

Verso 3. En el pie que ocupa la posición del 'arūd (delet en terminología hebrea), el editor propone שְִִׁירים 'asalariados'; personalmente me parece forzado, incluso rebuscado. En la fotografía puede leerse con cierta claridad שֶמי רוּם en poesía medieval y propia del piyyūt palestino. En cuanto al $\operatorname{darb}$,

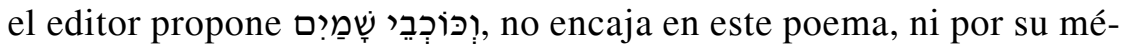
trica (faltaría la primera letra del watid entre yod y šin o habría que hacer móvil la yod) ni por su rima (exige un plural masculino, no un dual que es prácticamente un diptongo en este contexto). Sin poder leer con claridad el hemistiquio y sin certeza de que sea la lectura

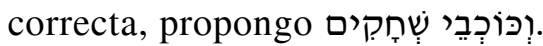

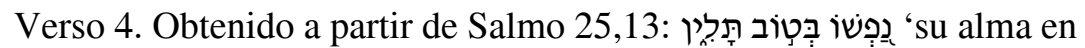

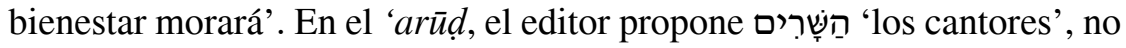
encaja en este poema por su métrica (donde es preceptivo un watid) y se propone ahora, a partir de la fotografía, חְסִידִים.

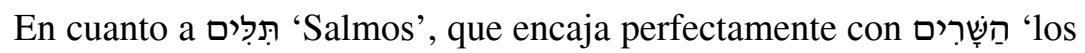
cantores', debe ahora sustituirse por דָּדִ הartir del pasaje de Salmo 25 empleado por el poeta y sin que haya problema alguno en identificar la nun final en la lápida.

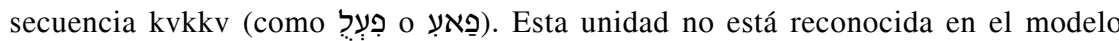
románico, que sólo reconoce dos de las seis unidades del modelo autóctono: sabab hafïf, sucesión de dos letras, la primera vocalizada y la segunda quiescente, es decir,

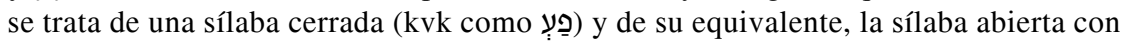
vocal larga ( $\mathrm{k} \overline{\mathrm{v}}$ como פַ) ya que las letras de alargamiento son en realidad consonantes quiescentes y conocida en hebreo como těnu'ah; y watid mağmū', sucesión de tres letras, donde la primera y la segunda están vocalizadas y la tercera quiescente, es

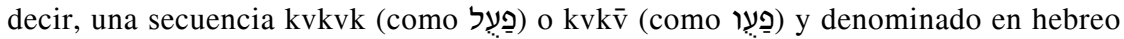
yated.

${ }^{22}$ CAsanovas Miró, Las inscripciones funerarias hebraicas, pág. 85. 


\subsection{Epitafio de un desconocido}

La segunda muestra de este estudio es la número 87 en el catálogo de Casanovas: «Epitafio de un desconocido» ${ }^{23}$. Como la anterior también apareció en la provincia de Gerona. La erosión y las fracturas de la pieza han provocado que se pierda el nombre del difunto pero no la fecha de su óbito: šěbat 5131 (enero-febrero 1371).

Se trata de una breve composición de cuatro versos seguida de la identificación del difunto y la data del óbito. A continuación ofrezco la propuesta de lectura de los cuatro versos con los que comienza el epitafio:

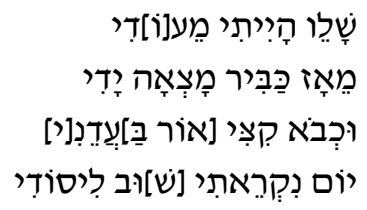

Traducción:

Tranquilo estuve durante mi existencia

Por entonces obtuve grandes bienes

Mas al llegar mi final [la oscuridad me envolvió]

El día que fui llamado de vuelta a mi esencia

El metro es mutadārak (conocido en terminología israelí como mišqal ha-těnu 'ot) en su forma mağzū' o parcial ${ }^{24}$ y modificado según la norma-

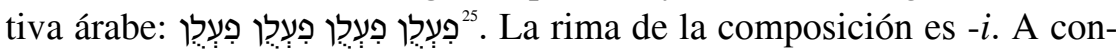
tinuación ofrezco su escansión en el modelo autóctono y romance, pero

\footnotetext{
${ }^{23}$ CAsanovas Miró, Las inscripciones funerarias hebraicas, pág. 98.

${ }^{24}$ Es decir, forma parcial del verso, al que se le ha suprimido un pie de cada hemistiquio.

${ }^{25}$ El primero en identificarlo fue David Yeluin, «The metrical Forms in the Poetry of Šemū'ēl Hannāgīd» (en hebreo), Studies of the Research Institute for Hebrew Poetry in Jerusalem 5 (1939) págs. 181-208: 192. Este pie no tiene que repetirse en todo el verso, puede alternarse con פַעִלֶן, lo cual es frecuente en árabe donde su uso en forma completa es bastate raro. Este metro acepta modificaciones en todos sus pies; por eso, una vez se le aplican modificaciones el metro llega incluso a cambiar de nombre. La modificación que sufren sus pies en este caso se conoce como qat ' originándose una medida llamada daff al-nufūs o fatr al-mi'zāb, y que al menos cuando coincide en número de sílabas (8) puede ser el hebreo mišqal ha-těnu'ot.
} 
dada la época tan tardía de su redacción no creo que se le pueda aplicar una transcripción de tradición andalusí como al caso anterior:

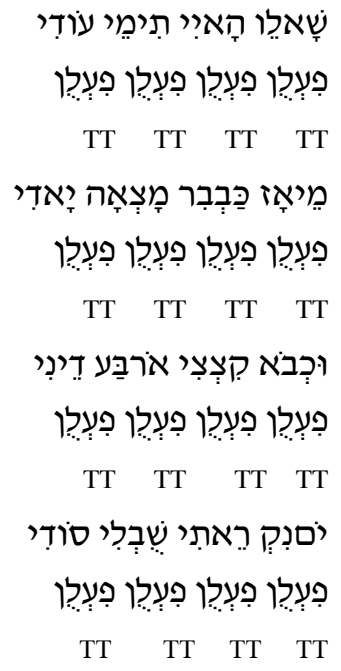

Verso 1. El poeta comienza el poema a partir de Job 16,12: שָׁלֵו הְְָיִתי 'tranquilo estaba' y retoma otro pasaje de este mismo libro en el siguiente verso.

Verso 2. El poeta retoma el libro de Job y toma el segundo hemistiquio

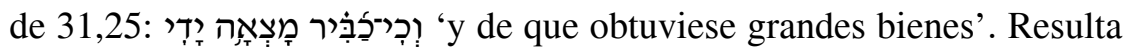
curioso que emplee el hemistiquio más oscuro del versículo y que precisa de la primera parte para ser interpretado.

Verso 3. Se sigue la reconstrucción propuesta por los distintos editores

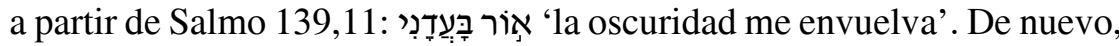
el poeta estaría recurriendo a un pasaje oscuro, donde la voz אicene el sentido de 'oscuridad, noche', tal y como confirma su uso en neohebreo

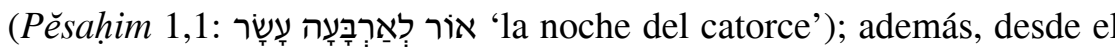
punto de vista métrico, tan sólo hay que suprimir la vocal de la gutural, lo cual es muy frecuente en poesía andalusí.

Verso 4. Todos los versos del poema se componen de ocho sílabas, por lo que la métrica de la composición no permite la prefijación de $ל$ al infinitivo שוּ, tal y como propone el editor ${ }^{26}$.

\footnotetext{
${ }^{26}$ CASAnovas Miró, Las inscripciones funerarias hebraicas, pág. 87
} 


\subsection{Epitafio de Yěhudah b. Reba ‘}

La tercera muestra es la número 134 en el catálogo de Casanovas: «Epitafio de Yěhudah b. Reba ${ }^{\text {}}{ }^{27}$. Proviene del cementerio de Sagunto donde ya estaba deteriorada cuando pasó por allí Mošeh b. Ḥabib antes del decreto de expulsión de los reyes católicos y es quizá una de las más célebres y estudiadas de todas las muestras conocidas ${ }^{28}$. La erosión y las fracturas de la pieza han provocado que se pierda la fecha del óbito y quizá la mitad del segundo verso -si es que realmente forma parte de la composición- aunque se conserva el nombre del difunto: Yěhudah b. Reba'.

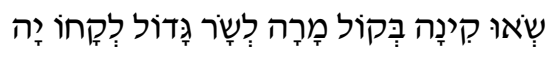

אזמציה

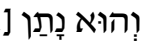

Traducción:

Entonad una elegía con voz amarga / por un gran príncipe que se ha llevado Dios Dió...

El metro es hazağ (conocido en terminología israelí como marnin), en principio parece que emplea su forma mağzzù ' o parcial, que es la más

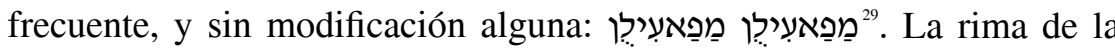
composición es $-a$. A continuación ofrezco su escansión en el modelo autóctono y romance y una propuesta de transcripción:

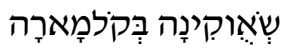

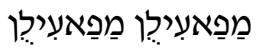

TTY TTY

śu'úqina baqúlmara

\footnotetext{
${ }^{27}$ CASANOVAS Miró, Las inscripciones funerarias hebraicas, págs. 134-135.

${ }^{28}$ Véase la bibliografía recopilada en CASANOvas Miró, Las inscripciones funerarias hebraicas, pág. 135.

${ }^{29}$ Se trata de uno de los metros más frecuentes en poseía hebrea andalusí junto con wāfir (měrubbeh).
}

SEFARAD, vol. 78:2, julio-diciembre 2018, págs. 313-328. isSN: 0037-0894. https://doi.org/10.3989/sefarad.018.010 


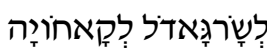

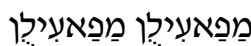

TTY TTY

laśárğadul laqáhuya

El texto conservado no presenta ninguna complicación a efectos métricos ni de interpretación. El epitafio continúa diciendo וְוֹ נָָת 'él dió', que encaja perfectamente en la métrica de la composición

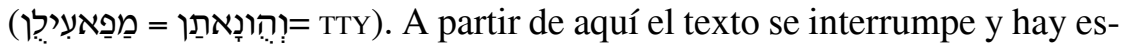
pacio perdido para dos pies más. El problema está en el larb final donde tan sólo parece que se pueda leer אַמִ̣ 'valientes', lectura que plantea dudas por su grafía defectiva y al que habría que prefijar לุ para que encaje en la métrica de la composición. Sin embargo, la rima en -a descarta esta

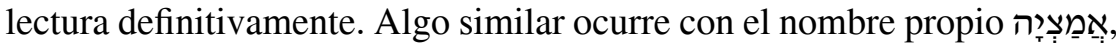
que respeta la rima pero desbarata la métrica del poema. Es cierto que este metro acepta un darb tipo פַעַעולון (TY) pero no puede aceptarse si no es adoptado desde el primer verso. Sí encaja en el metro y respeta la rima la lectura de Mošeh b. Ḥabib anterior a 1492:לאמציה, pero no me veo capaz de ofrecer una interpretación satisfactoria. La última posibilidad es que esta frase no sea parte de la composición, sino una fórmula estandarizada que incluso incluyese la fecha del óbito del finado y así sí se podría leer אמצים; al no tener acceso a la pieza original no sé en qué posición queda lugar para indicar la fecha del fallecimiento.

\subsection{Epitafio de Ishaq ben Yosef ben Cresp}

La cuarta y última muestra es la número 174 en el catálogo de Casanovas: «Epitafio de Ishaq ben Yosef ben Cresp» ${ }^{30}$. Proviene del cementerio de Toledo y tras ser reutilizada como dintel hoy está custodiada en el Museo Sefardí de dicha ciudad. La erosión y la mano del hombre han provocado la pérdida de la primera línea y de los comienzos de los primeros hemistiquios. Por fortuna, Luzzatto hizo una copia y gracias a ella puede recuperarse parte del texto.

\footnotetext{
${ }^{30}$ CASAnOVas Miró, Las inscripciones funerarias hebraicas, págs. 183-184.
} 
A diferencia de las otras muestras, ésta integra el nombre del difunto -Yiṣhaq b. Yosef b. Cresp- y la fecha de su óbito -18 de elul 5116 correspondiente al 23 de agosto del año 1356)- en el poema, sometiendo ambos datos a los caprichos de la métrica.

\begin{tabular}{|c|c|}
\hline 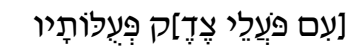 & 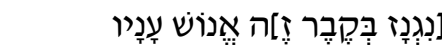 \\
\hline הָיָה וְגַם תָּמִים & 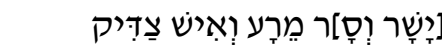 \\
\hline 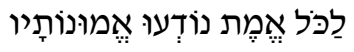 & 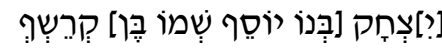 \\
\hline 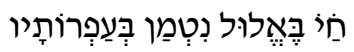 & 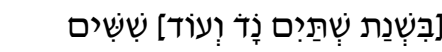 \\
\hline
\end{tabular}

Traducción:

Está depositado en esta tumba un hombre humilde

cual los actos de un piadoso eran sus actos

Recto, evitó el mal, un hombre justo

fue e incluso perfecto entre sus contemporáneos

Isaac hijo de José, su nombre es Ben Cresp

todos son conscientes de la sinceridad de sus creencias

En el año 2, 54 más 60

el 18 de elul yació en su polvo

El metro es $\operatorname{sar}^{`}$ (conocido en terminología israelí como mahir), emplea su forma completa conservando los seis pies originales, si bien ha modificado darb según la preceptiva clásica y ha contagiado a su 'arū

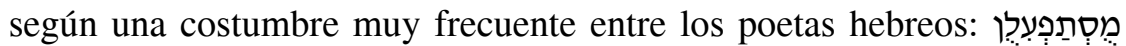

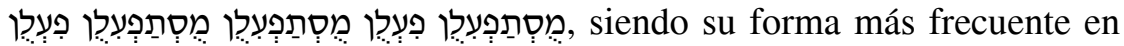
poesía hebrea $^{31}$. La rima de la composición es $-a w$ y el ritmo $\operatorname{tașr}^{{ }^{63}}$. A continuación ofrezco su escansión en el modelo autóctono y romance, dada su fecha tan tardía omito la propuesta de transcripción:

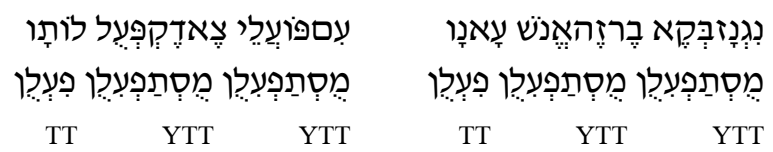

\footnotetext{
${ }^{31}$ Esta misma fórmula puede encontrarse, entre otros muchos poemas, en el epitafio compuesto por Mošeh ibn 'Ezra para ser grabado sobre la tumba del rabino de Lucena Yiṣ̣haq al-Fāsī (año 1103) y véase la traducción en Navarro Peiró, El tiempo y la muerte, págs. 149-151.

${ }^{32}$ Véase la nota 18.
}

SEFARAD, vol. 78:2, julio-diciembre 2018, págs. 313-328. ISSN: 0037-0894. https://doi.org/10.3989/sefarad.018.010 


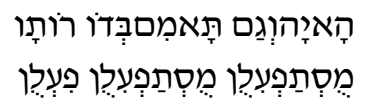

TT YTT YTT

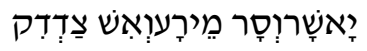

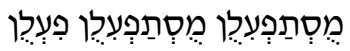
TT YTT YTT

Verso 1. Aunque la lectura del editor se ajusta a la métrica, prefiero

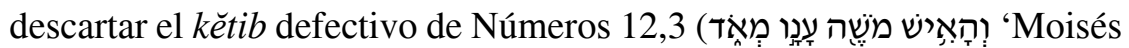
era un hombre extremadamente humilde') y recurrir a la grafía plena del

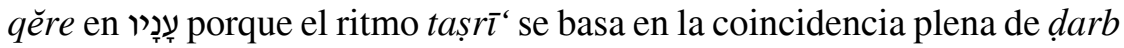
y 'arū $d$.

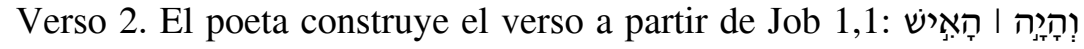
"era aquel hombre íntegro, recto, tem-

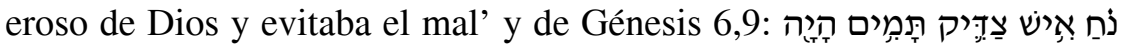
菓 'Noé era un hombre justo, fue perfecto entre sus contemporáneos'; en un claro intento de atribuir a la figura del difunto las mejores cualidades de Noé y Job.

Verso 3. El apellido familiar obliga al poeta a recurrir al menos a dos licencias: por un lado le obliga a emplear un 'arụd tipo פַאעִ lícito en este metro pero distinto al empleado en el resto de la composición; y por otro, tiene que obviar la doble consonancia final del apellido Cresp.

Verso 4. Hay un gran esfuerzo por parte del poeta en integrar la fecha del óbito en la composición, por lo que se ve obligado a descomponer el número para que éste encaje en la métrica de la composición. El editor data esta lápida el 18 de elul del año 5062, que se corresponde con el 20 de septiembre del año $1302^{33}$. Cabe la posibilidad de que el participio ग̦ 'vagó, emigró' sea en realidad parte del número de la fecha del óbito, tal y como sugiere el إעآ 'más' que le sigue, resultando $2+$ $54+60=$ [5]116. De ser así habría que fechar la lápida el 18 de elul del año 5116 de la Creación, correspondiente al día 23 de agosto de 1356 de la era cristiana.

\footnotetext{
${ }^{33}$ CASAnovas Miró (Las inscripciones funerarias hebraicas, pág. 183) prefiere interpretar 12 de septiembre de 1302 .
} 


\section{CONCLUSIÓN}

Como hemos visto, las tres primeras muestras responden al patrón «poema + nombre/fecha [+ prosa rimada]», mientras que la cuarta, a diferencia del resto, prefiere integrar la fecha y el nombre dentro de la composición, tal y como ocurre en la copia del epitafio de Šěmu'el b. Šošan, fechado en 1257 (metro wäfir) ${ }^{34}$, también del cementerio de Toledo y del que sólo nos queda el texto transmitido por Luzzatto; quizá se trate de una costumbre local propia de Toledo.

En todo caso, considero que la métrica, tanto en su modelo autóctono como romance, puede ayudarnos a reconstruir textos epigráficos deteriorados por el paso del tiempo y la mano del hombre. La presencia de poesía fúnebre es una costumbre que acompañó a los judíos de Sefarad desde la época del califato de Córdoba, a mediados del siglo x, hasta la expulsión a finales del siglo xv y más allá, siendo fácil encontrar estos formatos y tipos de composiciones en epitafios sitos en cementerios judíos de lugares tan alejados de la Península Ibérica como Ucrania ${ }^{35}$.

Recibido: $27 / 07 / 2018$

Aceptado: 23/10/2018

\footnotetext{
${ }^{34}$ José M. ${ }^{\mathrm{a}}$ Millás Vallicrosa y Francisco CAntera Burgos, Las inscripciones hebraicas de España (Madrid: CSIC, 1956) págs. 77-78.

${ }^{35}$ Véase por ejemplo el trabajo de Michael Nosonovsky, «Old Jewish Cemeteries in Ukraine: History, Monuments, Epitaphs», en The Euro-Asian Jewish Yearbook - 5768 (2007/2008), ed. Mikhail Chlenov (Moscow: Pallada, 2009) págs. 224-248: 235-237.
} 